\title{
Síndrome de Geschwind y la película Se7en
}

\author{
Pedro Gargantilla-Madera, Noelia Arroyo-Pardo, Francisco J. Alvarado-Lavado
}

Resulta muy difícil desligar nuestra profesión de las actividades de ocio y en algunas ocasiones, cuando disfrutamos de una buena película, llegamos a intuir la existencia de una patología en alguno de los protagonistas. Esto es lo que nos ha sucedido con la película Se7en: el análisis clínico del asesino en serie que aparece en ella hace pensar en que padecía un trastorno neurológico.

Un asesino en serie es una persona que asesina a tres o más personas en un período de 30 días o más, siendo su motivación la gratificación psicológica que le proporciona el crimen. Los asesinatos suelen llevarse a cabo de forma similar y las víctimas suelen compartir alguna característica [1].

La figura del asesino en serie ha sido llevada en múltiples ocasiones a la gran pantalla; uno de los ejemplos más conocidos es la película Se7en (David Fincher, 1995), en donde John Doe (interpretado por Kevin Spacey) comete sus crímenes en base a los pecados capitales. El análisis clínico de este asesino en serie conduce a pensar que resulta muy probable que su psicopatía tenga un sustrato neurológico, concretamente un trastorno interictal del lóbulo temporal.

John Doe piensa que ha sido el elegido para dar una lección de moralidad a la humanidad y utiliza los siete pecados capitales esbozados por Dante Alighieri en la sección del purgatorio de La divina comedia (gula, avaricia, pereza, lujuria, soberbia, ira y envidia) como motivación principal para cometer sus horrendos homicidios. La película se presenta dividida por los siete días de la semana y en cada uno de ellos se descubre uno de los crímenes. A medida que la acción transcurre, la tensión va in crescendo, así como el sadismo de los asesinatos. La película tiene un desenlace inesperado porque John Doe lleva al extremo su psicopatía al encarnar en sí mismo la envidia, cometiendo el crimen más atroz, asesinar a la esposa del detective Mills (Brad Pitt). Tras confesar su homicidio, esperará pacientemente a que el detective lo asesine, em- bargado por la ira, el último pecado capital, ante la impotente mirada de su compañero Somerset (Morgan Freeman).

John Doe es una persona fría, manipuladora, obsesiva (con la literatura), detallista y cruel hasta el extremo y con un marcado narcisismo (él se considera un justiciero que busca inmolarse y culminar su obra maestra de los siete pecados capitales). Su hipermoralismo tiene una base hiperreligiosa (en su apartamento los detectives encuentran múltiples crucifijos y biblias), a lo cual se une la hipergrafía (descubren 2.000 cuadernos con 250 páginas) y una escritura micrográfica. Todos estos síntomas pueden ser explicados por el síndrome de Geschwind.

Descrito por Waxman y Geschwind en 1975 [2], el síndrome se agrupa dentro de los estados interictales de las epilepsias focales del lóbulo temporal [3-5], en las cuales existen cambios patológicos en el sistema límbico [4]. Este síndrome se caracteriza por alteraciones en la conducta sexual de los pacientes (hiposexualidad), hiperagresividad, viscosidad, circunstancialidad, religiosidad y una tendencia compulsiva a escribir extensamente (hipergrafía) [4-6]. Estos sujetos se pueden volver tremendamente hipersensibles a las más pequeñas violaciones de sus principios y desarrollar conductas agresivas. Sus creencias morales y religiosas con frecuencia son el anticipo de actos de violencia.

\section{Bibliografía}

1. Chmelir SB. Serial killers. In Kastenbaum R, ed. Macmillan encyclopedia of death and dying. 2 ed. New York: Gale Group; 2003.

2. Waxman SG, Geschwind N. The interictal behavior syndrome in temporal lobe epilepsy. Arch Gen Psychiatry 1975; 32: 1580-6.

3. Holmes GL. Temporal lobe epilepsy. Epilepsy.com; 2004. URL: $\mathrm{http}: / /$ www.epilepsy.com/epilepsy/epilepsy_temporallobe. $\mathrm{html}$

4. Trimble M, Freeman A. An investigation of religiosity and the Gastaut-Geschwind syndrome in patients with temporal lobe epilepsy. Epilepsy Behav 2006; 9: 407-14.

5. Nowack WJ. Psychiatric disorders associated with epilepsy; 2004. URL: http://www.emedicine.com/neuro/topic604.htm

6. Ettinger AB, Kanner AM. Psychiatric issues in epilepsy. Baltimore: Lippincott Williams \& Wilkins; 2007.
Servicio de Medicina Interna; Hospital El Escorial (P. Gargantilla-Madera, N. Arroyo-Pardo, F.J. AlvaradoLavado). Universidad Francisco de Vitoria (P. Gargantilla-Madera). Madrid, España.

Correspondencia:

Dr. Pedro Gargantilla Madera. Servicio de Medicina Interna. Hospital El Escorial. Ctra. M-600 de Guadarrama a San Lorenzo de El Escorial, km 6,255. E-28200

San Lorenzo de El Escorial (Madrid).

E-mail: pgargantilla@yahoo.es (c) 2015 FEM 